4 Frank, C W, et al, fournal of Chronic Diseases, 1963, 16, 1293.

5 Dixon, W J, (editor), Biomedical Computer Programs. Los Angeles, University of California Press, 1971.

6 Rose, G, British fournal of Preventive and Social Medicine, 1968, 22, 12.

7 Gazes, P C, et al, Circulation, 1973, 48, 331.

${ }^{8} \mathrm{Kannel,} \mathrm{W} \mathrm{B,} \mathrm{and} \mathrm{Feinleib,} \mathrm{M,} \mathrm{American} \mathrm{fournal} \mathrm{of} \mathrm{Cardiology,} \mathrm{1972,}$ 29, 154.

${ }^{9}$ Blackburn, H, et al, in Preventive Cardiology, ed G Tibblin, A Keys, and L Werko, $n$ 54. New York, John Wiley and Sons, 1972

11 Reeves, T J, et al, American Fournal of Cardiology, 1974, 33, 423.

1 Levy, H, Annals of Internal Medicine, 1956, 44, 1123.

12 Nichol, E S, Phillips, W C, and Casten, G G, Annals of Internal Medicine, $1959,50,1158$

13 Beamish, R E, and Storrie, V M, in Anticoagulant Therapy in Ischaemic Heart Disease, ed E S Nichol. New York, Grune and Stratton, 1965.

14 Cheanvechai, C, et al, American fournal of Cardiology, 1973, 32, 901.

15 Wood, P, British Medical fournal, 1961, 1, 1779.
${ }^{16}$ Krauss, K R, Hutter, A M, and DeSanctis, R W, Archives of Internal Medicine, 1972, 129, 808.

17 Vakil, R J, Fournal of the Association of Physicians of India, 1966, 14, 259.

18 Fischl, S J, Herman, M V, and Gorlin, R, New England fournal of Medicine, 1973, 288, 1193.

19 Conti, C R, et al, American fournal of Cardiology, !973, 32, 745.

20 Bertolasi, C A, et al, American fournal of Cardiology, 1974, 33, 201.

21 World Health Organisation, Regional Office for Europe, The Prodromal Symptoms of Myocardial Infarction and Sudden Death. Copenhagen, WHO, 1971.

${ }^{22}$ Miller, D C, et al, Circulation, 1973, 47, 234.

23 Weinblatt, E, et al, American fournal of Public Health, 1968, 58, 1329.

24 Coronary Drug Project Research Group, fournal of Chronic Diseases, 1974, 27, 267.

${ }^{25}$ Conti, C R, et al, American fournal of Cardiology, 1975, 35, 129.

26 Bertolasi, C A, et al, American fournal of Cardiology, 1975, 36, 119.

\title{
Influence of maternal obesity on subcutaneous fat in the newborn
}

\author{
A G L WHITELAW
}

British Medical fournal, 1976, 1, 985-986

\section{Summary}

Skinfold thickness measurements were made at biceps, triceps, subscapular, and suprailiac sites on both sides on 265 full-term newborn infants. The mothers were classified as thin (25), normal (179), or obese (61) on the basis of their triceps skinfold thicknesses. At all skinfold sites the babies of the obese mothers were significantly fatter than the babies of normal mothers, and the babies of the normal mothers were significantly fatter than those of the thin mothers. There was a highly significant positive correlation between maternal triceps thickness and the baby's sum of skinfold thicknesses. Hypertension was common during the pregnancies of the obese mothers and was associated with a significant reduction in the babies' skinfold thicknesses. When each of the 61 obese mothers were matched for parity, blood pressure, and smoking habit with 61 non-obese mothers the babies of the obese mothers still had significantly greater skinfold thicknesses than the babies of non-obese mothers.

\section{Introduction}

Both genetic and environmental factors contribute to the wellrecognised familial tendency to obesity. ${ }^{1}$ Both excessive maternal weight in the first trimester and excessive weight gain in pregnancy are associated with increased birth weight. ${ }^{2} 3$ Ounsted and Taylor' found that small-for-gestational-age babies had mothers who, at delivery, were lighter than mothers of normal weight infants, and large-for-gestational-age babies had mothers who were taller and heavier than mothers of normal weight infants. Body weight, however, does not necessarily indicate the amount of fat in the body. People may be heavy without being fat if they are tall or have heavy bones, big

\footnotetext{
Institute of Child Health, London WC1 N1EH, and Queen Charlotte's Maternity Hospital, London W6 OXG
}

A G L WHITELAW, MRCP, research fellow muscles, or water retention. In the newborn, differences in head size may appreciably affect body weight. There are no reports linking actual fatness at birth with maternal fatness, and in this study skinfold thickness was measured to determine whether a correlation exists between these two variables.

\section{Subjects and methods}

Two-hundred-and-sixty-five mothers and their babies born after at least 37 completed weeks' gestation were examined within 48 hours of birth. The mothers were randomly selected from the list of deliveries in the labour ward, apart from some of the obese mothers, who were found by searching the wards, but without knowledge of the baby's size. Mothers with abnormal glucose tolerance test results were excluded, as were those with multiple births, babies with multiple or severe congenital malformations, and babies assessed as less than 37 completed weeks' gestation.

Skinfold thickness was measured with a Harpenden caliper, which can be read to $0 \cdot 1 \mathrm{~mm}$ and has surfaces small enough to be used on newborn babies. Brans et $a^{5}$ suggest that when the caliper is used in the newborn it should be left on the skinfold for 60 seconds because otherwise the presence of oedema in the neonate leads to a falsely high estimate of subcutaneous fat. I have confirmed their finding that the shorter the period of gestation and the more oedematous the baby the greater is the percentage drop in the skinfold reading over the first 60 seconds after application of the caliper. Measurements were recorded after 60 seconds' pressure at four sites on both sides: biceps skinfold, ${ }^{7}$ triceps skinfold, ${ }^{7}$ subcapsular skinfold, ${ }^{7}$ and suprailiac skinfold. ${ }^{6}$ A repeatability study of 104 pairs of duplicate measurements by one observer gave $95^{\circ}$ o confidence limits at the triceps site of $\pm 0.25 \mathrm{~mm}\left( \pm 6.9^{\circ}\right.$ of mean triceps skinfold $)$ and at the subscapular site of $\pm 0.35 \mathrm{~mm}$ ( $\pm 9 \cdot 1 \%$ of mean subscapular skinfold). The sum of eight readings (four on each side of the baby) had better repeatability, with $95^{\circ}$. confidence limits of $\pm 0.94 \mathrm{~mm}\left(3.5^{\circ} \circ\right.$ of mean sum of eight skinfolds), and also represented both trunk and limb fat. Like Farr, ${ }^{*}$ I found that skinfold thickness in newborn babies had a Gaussian distribution and could therefore be analysed statistically without logarithmic transformation.

Birth weight was recorded by midwives on beam scales. Crown to heel length was measured on a Cardiff neonatometer and occipitofrontal head circumference with a papertape measure.

Each mother's left triceps skinfold was measured and compared with the standards for young women. ${ }^{7}$ Mothers with triceps skinfold thicknesses above the 90 th centile $(24 \mathrm{~mm})$ were classified as obese, those with readings between the 10th and 90th centile as normal, and those with readings below the 10 th centile $(10.2 \mathrm{~mm})$ as thin. The mothers gave their informed consent to the study. The application of 
the caliper to the mother's arm showed her that the procedure to be carried out on the baby was painless. Weight and blood pressure were measured routinely during pregnancy in the antenatal clinic using a beam balance and a standard mercury sphygmomanometer with a one-size cuff. Mothers were defined as hypertensive if they had a systolic pressure of at least $140 \mathrm{~mm} \mathrm{Hg}$ or a diastolic pressure of at least $90 \mathrm{~mm} \mathrm{Hg}$ at least once during the pregnancy. Smoking history was elicited at the time of the examination and mothers were classified as smokers if they had smoked at least one cigarette a day throughout pregnancy and non-smokers if they had smoked less than one cigarette a day throughout pregnancy. ${ }^{9}$

Unless otherwise stated data were analysed by Student's $t$ test.

\section{Results}

Table I shows that at every site the babies of the obese mothers had significantly fatter skinfolds than the babies of normal mothers, and the babies of the normal mothers were fatter than the babies of the thin mothers, although at the subscapular site the difference was not statistically significant. A moderate but significant positive correlation was found between maternal triceps skinfold thickness (logarithmic transformation ${ }^{\circ}$ ) and the sum of baby's eight skinfolds (Pearson $r=0.33 ; P<0.001)$. Maternal weight in the first trimester also correlated with the sum of the baby's skinfold thicknesses (Pearson $\mathrm{r}=0.28 ; \mathrm{P}<0.01$ ), as did maternal weight gain during pregnancy (Pearson $r=0.27 ; P<0.01)$. There was no significant difference between the obese, normal, and thin mothers in length of pregnancy or the proportion of boy to girl infants.

TABLE I-Mean skinfold thickness at birth $( \pm 1 S D)$ related to maternal skinfold

\begin{tabular}{|c|c|c|c|}
\hline & \multicolumn{3}{|c|}{ Maternal triceps skinfold centiles } \\
\hline & $>90$ th (obese) & 10th-90th (normal) & $<10$ th (thin) \\
\hline $\begin{array}{l}\text { No of infants ... } \\
\text { Skınfold thickness (mm) }\end{array}$ & 61 & 179 & 25 \\
\hline 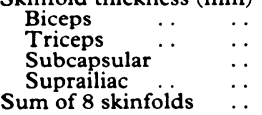 & $\begin{aligned} & 3 \cdot 3 \pm 0 \cdot 7^{*} \\
& 4 \cdot 4 \pm 0 \cdot 9^{*} \\
& 4 \cdot 6 \pm 1 \cdot 2^{*} \\
& 3 \cdot 7 \pm 0 \cdot 9^{*} \\
& 32 \cdot 2 \pm 6 \cdot 1^{*}\end{aligned}$ & $\begin{array}{c}3 \cdot 0 \pm 0 \cdot 6+ \\
3 \cdot 9 \pm 0 \cdot 8^{\dagger} \\
4 \cdot 0 \pm 1 \cdot 0 \\
3 \cdot 3 \pm 0 \cdot 7^{+} \\
28 \cdot 6 \pm 5 \cdot 7^{\ddagger}\end{array}$ & $\begin{array}{r}2 \cdot 7 \pm 0.5 \\
3 \cdot 6 \pm 0.9 \\
3 \cdot 6 \pm 1 \cdot 0 \\
2 \cdot 8 \pm 0 \cdot 7 \\
25 \cdot 4 \pm 5 \cdot 8\end{array}$ \\
\hline
\end{tabular}

* Significantly greater than skinfolds of babies of normal mothers $(P<0.001)$. Significantly greater than skinfolds of babies of thin mothers:

Table II shows birth weight, length, and head circumference in the babies of the three groups of mothers and also the parity and smoking habits of the mothers. Birth weight showed the same trend as skinfold thicknesses, and the differences were statistically significant;

TABLE II-Maternal skinfold thickness related to mean size at birth ( $\pm 1 S D)$, smoking, and parity

\begin{tabular}{|c|c|c|c|}
\hline \multirow{2}{*}{ Full term infants } & \multicolumn{3}{|c|}{ Maternal triceps skinfold centiles } \\
\hline & $>90$ th (obese) & 10th-90th (normal) & $<10$ th (thin) \\
\hline $\begin{array}{lc}\text { No of infants } & \ldots \\
\text { Birth weight }(\mathbf{k g}) & \ldots \\
\text { Length }(\mathrm{cm}) & \ldots \\
\text { Head circumference } & (\mathrm{cm}) \\
\text { No of multiparae } & \ldots \\
\text { No of smokers } & \ldots\end{array}$ & $\begin{array}{c}61 \\
3 \cdot 6 \pm 0 \cdot 6+ \\
53 \cdot 2 \pm 2 \cdot 8 \\
35 \cdot 2 \pm 1 \cdot 4+ \\
38\left(63^{\circ}+\right)^{+} \\
5\left(8_{0}^{\circ}\right)\end{array}$ & $\begin{array}{c}179 \\
3 \cdot 4=0.6+ \\
52 \cdot 5 \pm 5.0 \S \\
34 \cdot 0+1.6 \\
91\left(511^{\circ}\right) \\
30\left(17^{\circ}\right)\end{array}$ & $\begin{array}{c}25 \\
3 \cdot 0 \pm 0 \cdot 6 \dagger \\
50 \cdot 4 \div 3 \cdot 5 \\
34 \cdot 2+2 \cdot 1 \\
9\left(36^{\circ}\right) \\
11\left(44^{\prime \prime \prime}\right)\end{array}$ \\
\hline
\end{tabular}

* $\chi^{2}$ test for trend was significant $P<0.05$.

+ Differences in mean birth weights were statistically significant $(P<0.01)$. †Significantly greater than mean head circumference of babies of normal mothers $(\mathrm{P}<0.001)$

Significantly greater than mean length of babies of thin mothers $(P<0.05)$.

for length only the difference between the babies of the thin and the normal mothers reached statistical significance; and for head circumference only the difference between the babies of the normal and the obese mothers was significant. The obese mothers had a greater percentage of multiparae than the normal and thin mothers, although this difference was not statistically significant. The group of thin mothers had a greater percentage of smokers than the normal mothers, who in turn included more smokers than the group of obese mothers. These differences were statistically significant.
Table III shows that 39 of the 61 obese mothers had raised blood pressure during pregnancy. The sum of the skinfold thicknesses of their babies was significantly lower than that of the babies of the 22 normotensive obese mothers. A similar difference was found for birth weight and length, but not for head circumference. The hypertensive and normotensive groups did not differ in length of pregnancy.

In an attempt to assess the effect of maternal obesity without the influence of parity, maternal hypertension, or maternal smoking habits each of the 61 obese mothers was matched with a non-obese mother with the same parity, presence or absence of hypertension, and presence or absence of smoking during pregnancy. When the matched groups were compared the babies of the obese mothers were still significantly fatter than those babies of non-obese mothers, but there was no significant difference in birth weight, length, or head circumference.

TABLE III-Mean size at birth $( \pm 1 S D)$ of babies of obese mothers, related to blood pressure

\begin{tabular}{|c|c|c|c|c|}
\hline & & \multicolumn{2}{|c|}{$\begin{array}{l}\text { Maternal triceps skinfold }>90 \text { th } \\
\text { centile }\end{array}$} & \multirow{2}{*}{$\begin{array}{l}\text { Student's } \\
t \text { test }\end{array}$} \\
\hline & & Hypertensive & Normotensive & \\
\hline $\begin{array}{l}\text { No of infants } \\
\text { Birth weight }(\mathrm{kg}) \quad \ldots \\
\text { Length }(\mathrm{cm}) \\
\text { Head circumference }(\mathrm{cm}) \\
\text { Sum of } 8 \text { skinfolds }(\mathrm{mm})\end{array}$ & $\begin{array}{l}\cdots \\
\cdots \\
\cdots \\
\cdots\end{array}$ & $\begin{array}{rl}39 & 39 \\
3 \cdot 5 & 0 \cdot 5 \\
52 \cdot 6 & 2 \cdot 8 \\
35 \cdot 0 & 1 \cdot 4 \\
30 \cdot 6 & 6 \cdot 2\end{array}$ & $\begin{array}{rl}3.9 & 22 \\
3 \cdot 9 & 0 \cdot 6 \\
54 \cdot 2 & 2 \cdot 9 \\
35 \cdot 4 & 1 \cdot 5 \\
35 \cdot 2 & : 6 \cdot 4\end{array}$ & $\begin{array}{l}\mathrm{P}<0.01 \\
\mathrm{P}<0.05 \\
\mathrm{P}>0.05 \\
\mathrm{P}<0.01\end{array}$ \\
\hline
\end{tabular}

\section{Discussion}

This study shows that maternal obesity is associated with increased subcutaneous fat in the newborn. Although obese mothers tend to smoke less and to have greater parity than nonobese mothers, increased fatness of the babies is still found when these two factors are allowed for. Possible explanations include increased placental transfer of free fatty acids, inheritance of a lower metabolic rate, and decreased physical activity in utero.

Hypertension in obese pregnant women is associated with a reduction in the subcutaneous fat of the fetus. Dixon and Robertson ${ }^{10}$ found obliterative vascular changes in the placental bed of patients with hypertension in pregnancy. Such vascular lesions might interfere with placental transfer of nutrients.

The fact that obese mothers have fatter babies at birth than normal mothers is of interest because it throws light on fetal nutrition. More important is that paediatricians, general practitioners, and health visitors should be aware that these babies have a familial tendency to obesity and are already fatter than normal at birth. Thus they have a special need for dietary advice and periodic growth measurements in the hope of preventing permanent obesity.

I am grateful to Professor J K Lloyd, Professor O H Wolff, and Dr D Harvey for their constant help, criticism, and encouragement.

\section{References}

${ }^{1}$ Brook, C G D, Huntley, R M C, and Slack, J, British Medical fournal, $1975,1,719$.

${ }^{2}$ Kerr, M, fournal of Obstetrics and Gynaecology of the British Commonwealth, 1962, 69, 988.

${ }^{3}$ Singer, J E, Westphal, $M$, and Niswander, K, Obstetrics and Gynecology, $1968,31,417$.

4 Ounsted, M, and Taylor, M E, Developmental Medicine and Child Neurology, 1971, 13, 421 .

5 Brans, Y W, et al, Pediatric Research, 1974, 8, 214.

- McGowan, A, Jordan, M, and MacGregor, J, Biology of the Neonate, $1975,25,66$.

: Tanner, J M, and Whitehouse, R H, Archives of Disease in Childhood, 1975, 50, 142

8 Farr, V, Archives of Disease in Childhood, 1966, 41, 301.

9 Butler, N R, and Alberman, E D, Perinatal Problems. Edinburgh, Livingstone, 1969.

10 Dixon, H G, and Robertson, W B, Fournal of Obstetrics and Gynaecology of the British Commonwealth, 1958, 65, 803. 